\title{
Club, country and clinicians united: ensuring collaborative care in elite sport medical handovers
}

\author{
Richard Weiler ำ , 1,2,3,4 Richard Collinge ำ ,' Josh Ewens, ${ }^{1}$ \\ Vincent Gouttebarge (1) , $5,6,7,8$ Andrew Massey (1) ${ }^{9}$ \\ Pippa Bennett, ${ }^{4,10,11}$ Kelly Smith, ${ }^{12}$ Osman Hassan Ahmed (1) 3,13,14
}

\begin{abstract}
Medical handovers are fundamental to optimal patient care but can be a source of errors in clinical care with important implications on patient welfare and safety. ${ }^{1-4}$ Care of international athletes presents unique challenges to open and effective communication between medical teams. Handover of complete medical records should occur with athlete consent between medical teams on the transfer of an athlete between clubs. There are currently no specific guidelines or published recommendations advising sports and exercise medicine clinicians about medical handovers. The aim of this editorial is to provide a checklist of recommendations for the handover of elite athlete care between clubs and national medical and sports science teams, with lessons shared from professional football (soccer).
\end{abstract}

'Department of Medicine and Sports Science, West Ham United Football Club, Romford, Essex, UK ${ }^{2}$ Amsterdam Collaboration on Health and Safety in Sports, Department of Public and Occupational Health, EMGO Institute for Health and Care Research, VU University Medical Center, Amsterdam, The Netherlands ${ }^{3}$ Para Football Foundation, Amsterdam, The Netherlands ${ }^{4}$ Fortius Clinic, London, UK

${ }^{5}$ Amsterdam UMC, University of Amsterdam, Department of Orthopaedic Surgery, Amsterdam Movement Sciences, Meibergdreef 9, Amsterdam, The Netherlands

${ }^{6}$ Section Sports Medicine, University of Pretoria, Pretoria, South Africa

7 Amsterdam Collaboration on Health \& Safety in Sports (ACHSS), Amsterdam UMC IOC Research Center of Excellence, Amsterdam, The Netherlands

${ }^{8}$ Football Players Worldwide (FIFPRO), Hoofddorp, The Netherlands

${ }^{9}$ Fédération Internationale de Football Association, Zurich, Switzerland

${ }^{10}$ British Equestrian Federation, Abbey Park, Stareton, Kenilworth, UK

${ }^{11}$ The Football Association (FA), St Georges Park, Burton-Upon-Trent, UK

${ }^{12}$ London, UK

${ }^{13}$ University Hospitals Dorset NHS Foundation Trust, Poole, UK

${ }^{14}$ School of Sport, Health and Exercise Science, University of Portsmouth, Portsmouth, UK

Correspondence to Prof. Vincent Gouttebarge, Amsterdam UMC, Department of Orthopaedic Surgery, Meibergdreef 9, Amsterdam, Netherlands; v.gouttebarge@amsterdamumc.nl

\section{INTERNATIONAL HANDOVERS IN ELITE} SPORT

Accurate clinical records are key to patient safety and protect patients and clinicians in sports medicine and science. In professional football for instance, there are currently 211 men's $^{5}$ and 159 women's ${ }^{6}$ FIFA registered international football teams. Squads generally consist of 23 players, resulting in up to 8487 players being available for 'call up' to international fixtures. Medical and sports science resources vary widely across clubs, sports, sexes, countries, age groups and Para sports, and information available for handover will vary accordingly, creating challenges to meet consistent standards.

\section{SHARING DATA}

Many professional sports clubs monitor and handle a vast amount of medical and sports science data to manage injury/illness, load, training regimes, injury prevention, playing availability and support optimal performance. Sources of data include traditional medical records, rate of perceived exertion, global position systems, heart rate monitoring, and various adapted patient reported outcome measures and sleep metrics. Where resources permit, these types of data are often continuously monitored, regularly reviewed, and discussed by medical and sports science multidisciplinary teams within professional sports clubs.

These data are important to medical staff of national teams to maintain continuity of care and avoid significant changes which can place athletes at risk of injury and sub-optimal performance. By providing these data as part of an athlete's medical handover, medical staff of the club and national teams will be better able to serve the needs of the athlete, ${ }^{7}$ both in performance and their safety/well-being. Some national teams request completion of medical 'fitness for duty' forms which may provide some limited information but are often not a complete medical handover that provides all necessary information to transfer care from one team to another. Since the physical demands of international and club sport can differ, thoughtful training modifications and transitions are needed to mitigate injury risk.

\section{THE ATHLETE'S ROLE IN HANDOVERS}

Athletes are a key partner in their own medical care and must make autonomous, informed decisions on all associated risks to performance and injury which can also affect their quality of life, physical and mental health, and careers. Athletes compete in different teams and might move between clubs and national teams several times per season. A prerequisite to medical handovers is the consent of the athlete to share their medical information; consent (verbal and/or written) should be documented.

Medical and performance data are sensitive. All stakeholders have a responsibility to ensure this information is readily and securely available for the benefit of the athlete. There are several ways to ensure safe handling of data (eg, complying with General Data Protection Regulation (GDPR) in the European Union). One method is for athletes to be given their 'own' handover. Alternatively, electronic health and performance (science) records can be consensually shared between club and national medical teams.

\section{RECOMMENDATIONS FOR ATHLETE- CENTRED HANDOVERS}

Language and medical culture may differ between clinicians involved in medical handovers for international athletes, creating additional challenges for a sufficient and accurate transfer of information to safeguard the well-being of the athlete for both club and country. Table 1 is a checklist of pre, and post camp written medical and sports science handover information which may assist a safe and comprehensive handover, ensure medicolegal accountability, but most importantly protect the welfare and interests of international athletes. Club and country medical and sports science counterparts should agree on their preferred communication formats and personnel. Medical records, performance data, results and reports should always be shared in written format. Urgent medical updates on injuries or illness during a camp or competition should be actioned as soon as possible and in a suitable format such as by phone call, messaging, or confidential 
Table 1 Medical handover checklist for athletes before, during and immediately after international duty

\begin{tabular}{|c|c|c|}
\hline & Information for handover & $\begin{array}{l}\text { Specifics to be included in handover } \\
\text { (sports science data available will vary) }\end{array}$ \\
\hline \multirow[t]{9}{*}{ Essential } & Athlete consent & Athlete provided consent to share medical and personal data (ideally written and signed). \\
\hline & $\begin{array}{l}\text { Current and chronic injuries and } \\
\text { illnesses }\end{array}$ & $\begin{array}{l}\text { All recent acute or chronic time-loss from training/competition injuries and illness have been outlined. } \\
\text { Club has been notified by international medical team of any new injury or illness occurring on international duty at earliest } \\
\text { opportunity. } \\
\text { Notwithstanding emergency medical care, club and national team medical teams should collaborate and ideally agree on any } \\
\text { major treatment decisions or interventions such as surgery and injections. }\end{array}$ \\
\hline & Significant past injuries and illness & Full details provided for any surgical procedures/interventions and extended periods of rehabilitation. \\
\hline & $\begin{array}{l}\text { Medications, allergies and } \\
\text { supplementation }\end{array}$ & $\begin{array}{l}\text { Current or recently administered medications and supplements should be clearly communicated. (Essential for prescribing safety } \\
\text { and antidoping purposes.) } \\
\text { Allergies to medicines, food, and anything else notable (eg, bee stings). } \\
\text { Current or intended therapeutic use exemption (TUE) forms provided. } \\
\text { Consider providing vaccination history. }\end{array}$ \\
\hline & Treatments & Details provided regarding any recent or regular physiotherapy, manual therapy, osteopathy, and acupuncture. \\
\hline & Recent investigations and results & $\begin{array}{l}\text { Any relevant radiology and blood test results included. } \\
\text { Details of last cardiac screening date and results provided. }\end{array}$ \\
\hline & Athlete decision-making & $\begin{array}{l}\text { Athlete has been central to decision if playing with an injury on international duty, and club medical staff should be involved and } \\
\text { informed in decision making process. } \\
\text { If preceding internationals a player is playing with an issue or risk, the international team medical staff has been involved in } \\
\text { management decisions with player consent. Coach to coach agreement should also be encouraged, considered and sought. } \\
\text { National teams choosing to target developmental goal setting have discussed such targets with club medical staff to ensure } \\
\text { changes to gym or loading programmes are aligned and managed safely. This may require more regular communication between } \\
\text { the relevant parties and will avoid confusion for athletes when they move between club and country. }\end{array}$ \\
\hline & Next of kin contact details & \\
\hline & $\begin{array}{l}\text { Emergency Contact Details for Club } \\
\text { Doctor/Club Head of Medical and } \\
\text { Sports Science Department }\end{array}$ & \\
\hline \multirow[t]{2}{*}{ Desirable } & Gym Programme & $\begin{array}{l}\text { Details provided of any tailored strength and conditioning programme the athlete is currently undertaking or recent amendments. } \\
\text { Inclusion of detailed gym loads (eg, repetitions, weights, sets, tempo) alongside usual timings in microcycle (typically a } 1 \text { week } \\
\text { training block). } \\
\text { Ideally, unique gym exercises are provided through photo/video with notations to describe specifics, in order to avoid confusion or } \\
\text { misunderstanding and promote consistency between club and country programmes. }\end{array}$ \\
\hline & Training and match data & $\begin{array}{l}\text { Training load data (rates of perceived exertion (RPE) and total training duration) for the previous month are provided, which may } \\
\text { include objective and subjective data (eg, patient reported outcome measures (PROMS) and session RPE's). } \\
\text { If available, additional objective data for matches and training are provided, such as global positioning system (GPS), heart rate } \\
\text { monitoring (HRM), early morning heart rate and RR interval data). }\end{array}$ \\
\hline
\end{tabular}

email, with written complete medical records to follow, when fully collated.

\section{IMPACT OF COVID-19 ON HANDOVERS}

COVID-19 continues to impact international sport. Many federations, sports and countries have published, and regularly update their own COVID-19 guidelines. Medical teams should ensure compliance with prevention and testing measures. The safe handling, reporting and sharing of all COVID-19 related data including recent testing results, any potential COVID-19 exposures, prior infections, and subsequent cardiac investigations is paramount. All stakeholders have a responsibility, including national and international sports federations and their governing boards, to agree and implement appropriate policies and procedures to support and protect both medical teams and athletes.

\section{CONCLUSION}

Comprehensive structured medical and sports science handovers between clinicians of club and country can be easily collated and shared to improve the care and welfare of international athletes.
Our checklist can be used to ensure and support an effective medical handover.

Twitter Vincent Gouttebarge @vgouttebarge, Andrew Massey@andy_massey, Pippa Bennett @pbennett67, Kelly Smith @kelly_smith10 and Osman Hassan Ahmed @osmanhahmed

Contributors RW drafted the initial document following discussions with RC, JE and OHA. RW, OHA, $\mathrm{RC}$ and JE drafted the initial checklist. All authors provided opinion, comments and amendments to subsequent versions. All authors approved the final version of the manuscript.

Funding The authors have not declared a specific grant for this research from any funding agency in the public, commercial or not-for-profit sectors. 
Competing interests None declared.

Patient consent for publication Not required.

Provenance and peer review Not commissioned; externally peer reviewed.

\section{(2)}

\section{OPEN ACCESS}

Open access This is an open access article distributed in accordance with the Creative Commons Attribution Non Commercial (CC BY-NC 4.0) license, which permits others to distribute, remix, adapt, build upon this work non-commercially, and license their derivative works on different terms, provided the original work is properly cited, appropriate credit is given, any changes made indicated, and the use is non-commercial. See: http:// creativecommons.org/licenses/by-nc/4.0/.

(C) Author(s) (or their employer(s)) 2021. Re-use permitted under CC BY-NC. No commercial re-use. See rights and permissions. Published by BMJ.

\section{Check for updates}

To cite Weiler R, Collinge R, Ewens J, et al. $\mathrm{Br} J$ Sports Med Epub ahead of print: [please include Day Month Year]. doi:10.1136/bjsports-2021-104146

Accepted 11 June 2021

Br J Sports Med 2021:0:1-3.

doi:10.1136/bjsports-2021-104146

\section{ORCID iDs}

Richard Weiler http://orcid.org/0000-0001-5835-

2939

Richard Collinge http://orcid.org/0000-0003-1876-

1062

Vincent Gouttebarge http://orcid.org/0000-0002-0126-

4177

Andrew Massey http://orcid.org/0000-0002-8253-

932X

Osman Hassan Ahmed http://orcid.org/0000-0002-

1439-0076

\section{REFERENCES}

1 Merten H, van Galen LS, Wagner C. Safe handover. BMJ 2017;359:j4328.

2 GMC. Good medical practice. GMC, United Kingdom, 2019. Available: http://www.gmc-uk.org/guidance/ good_medical_practice.asp

3 Medical Protection Society Limited (MPS). Available: https://www.medicalprotection.org/uk/articles/remotehandovers-with-colleagues-reducing-the-risks

4 MDU. Avoiding medical errors on the ward. Available: https://www.themdu.com/guidance-and-advice/ journals/wardround-april-2014/avoiding-medical-errorson-the-ward

5 FIFA. Fifa member associations. Available: https://www. fifa.com/associations

6 FIFA. Women's ranking. Available: https://www.fifa.com/ fifa-world-ranking/ranking-table/women

7 Ekstrand J, Lundqvist D, Davison $\mathrm{M}$, et al. Communication quality between the medical team and the head coach/manager is associated with injury burden and player availability in elite football clubs. $\mathrm{Br}$ J Sports Med 2019;53:304-8 